Journal of Clinical Investigation

Vol. 41, No. 6, 1962

\title{
SOME HORMONAL, METABOLIC, AND NUTRITIONAL FACTORS INFLUENCING LIPID PEROXIDATION BY RAT ADIPOSE TISSUE IN VITRO *
}

\author{
By WILLIAM G. BLACKARD, $\dagger$ MICHAEL F. BALL $\dagger$ AND FRANK L. ENGEL $\ddagger$
}

(From the Departments of Medicine and Physiology and the Division of Endocrinology, Duke University Medical Center, Durham, N. C.)

(Submitted for publication November 27, 1961 ; accepted February 9, 1962)

The action of adrenaline, noradrenaline, ACTH, and other hormones in stimulating the release of free fatty acids (FFA) by hydrolysis of triglycerides in adipose tissue incubated in vitro is now well established (1). These same hormones also profoundly influence the utilization of glucose by adipose tissue. There is considerable evidence that the alterations in carbohydrate utilization noted in the in vitro studies may be consequences of changing intracellular concentrations of FFA, resulting from lipolysis, rather than direct and independent effects of the hormones on glucose metabolism (2-4).

Since the triglycerides involved in lipolysis include both saturated and unsaturated fatty acids, the possibility occurred to us that peroxidation of the unsaturated fatty acids might occur under the conditions of aerobic incubation customarily employed with adipose tissue. The peroxides and hydroperoxides which result from the oxidation of various polyunsaturated fatty acids are unstable and decompose to products which include malonylaldehyde, as well as other compounds which yield malonylaldehyde on acid hydrolysis $(5,6)$. Malonylaldehyde reacts with 2-thiobarbituric acid (TBA) to form a pink chromogen with an absorption maximum at $530 \mathrm{~m} \mu$ (7-9) (Figure 1). The TBA reaction has been widely used in the study of the lipid peroxidation that occurs in response to ultraviolet irradiation (10), ionizing radiation (11), during vitamin E deficiency (12), and in the development of rancidity of fats and oils

\footnotetext{
* Supported by the Medical Research and Development Division, Office of the Surgeon General, Department of the Army (Contract no. DA-49-007-MD-134), and the National Institute of Arthritis and Metabolic Diseases, USPHS (Grant no. A-1324).

$\dagger$ Trainee, supported by Training Grant 2A-5074 from the National Institute of Arthritis and Metabolic Diseases. $\ddagger$ Please address reprint requests to F.L.E.
}

(5). While the TBA reaction does not measure the lipid peroxides themselves, most investigators agree that it may be employed as an index of lipid peroxidation. In this report the term "lipid peroxides" is used with the understanding that only products of peroxidation and not the peroxides themselves are being measured. Limitations of the TBA method have been discussed by Zalkin and Tappel (13).

Peroxidation of unsaturated fatty acid emulsions takes place as a nonenzymatic reaction in the presence of oxygen and ferrous ion, or photochemically with ultraviolet irradiation. Similarly, during aerobic incubation of various tissues (prepared as minces, slices, or homogenates) or of mitochondrial and microsomal suspensions, lipid peroxides may be formed, presumably, by a nonenzymatic mechanism. In such systems ferrous ion and ascorbic acid are required for maximal peroxide formation. Current data suggest that co-oxidation of unsaturated lipid and ascorbic acid occurs as a coupled reaction with ferrous ion. Ferrous ion reacts with the unsaturated fatty acid with the formation of the peroxide and $\mathrm{Fe}^{+++}$. Ascorbic acid, or similar reducing agents, then reduce $\mathrm{Fe}^{+++}$to $\mathrm{Fe}^{++}$to permit the cycle of coupled oxidation to continue (14).

Lipid peroxides are highly toxic for a number of enzyme systems and, indeed, have been implicated as damaging agents in the response to ionizing radiation $(11,15)$ and in vitamin $\mathrm{E}$ deficiency $(12,13,16)$. The production of lipid peroxides during incubation of adipose tissue thus might have important implications for the interpretation of metabolic events in this tissue.

In another report, evidence for lipid peroxidation in adipose tissue during in vitro incubation is presented and some of the factors influencing the reaction are considered (17). Briefly, it was found that a TBA-reacting chromogen was de- 

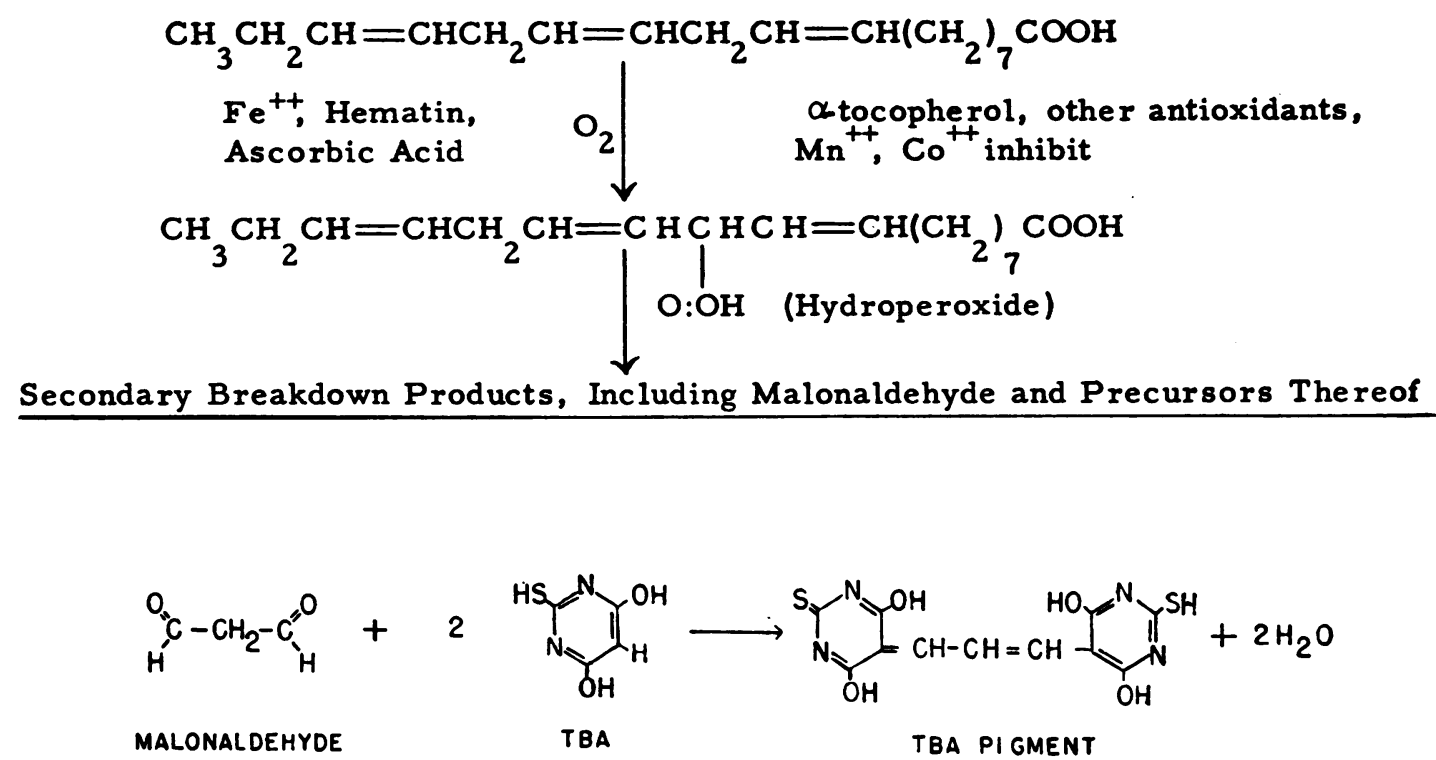

Fig. 1. Oxidation of linolenic acid and the thiobarbituric aCid Reaction.

tectable in both tissue and medium during aerobic incubation of adipose tissue in a Krebs-Ringer bicarbonate buffer containing crystalline bovine or human serum albumin. The quantity formed was increased in the presence of hormones promoting lipolysis, and could be decreased by incubation in an atmosphere of 95 per cent $\mathrm{N}_{2}, 5$ per cent $\mathrm{CO}_{2}$ or by adding an antioxidant to the medium. The substances reacting with TBA were found not to be extracted with FFA in the procedure of Dole and Meinertz (18) and were not bound to albumin when released into the medium. Nevertheless, human and bovine serum albumin increased peroxidation by adipose tissue in vitro. This activity of albumin was shown to be due to factors which could be largely, but not completely, removed by dialysis and treatment of the albumin with ethylenediamine tetraacetate (EDTA). The factors in albumin which promoted peroxidation were not identified chemically but could be replaced by $\mathrm{Fe}^{++}$ and ascorbic acid. Evidence was presented that peroxidation during incubation occurred within the adipose tissue cell rather than in the medium. In the present report some of the metabolic, hormonal, and nutritional factors influencing lipid peroxidation by adipose tissue in vitro are considered.

\section{METHODS AND MATERIALS}

Male Wistar strain rats from our own colony, weighing 170 to $230 \mathrm{~g}$ and fasted for 16 hours overnight, were used, except in those experiments in which 150 - to 180 -g hypophysectomized and intact male rats obtained from the Charles River Breeding Laboratory were used. Rats were hypophysectomized 3 weeks before use and were compared to controls of the same weight. The animals were fed Purina rat chow. Before transfer to the laboratory 1 to 2 days before use, they had received supplements of liver pudding (19) and lettuce twice a week. Epididymal fat pads were removed after the rats were anesthetized with $5 \mathrm{mg}$ of sodium pentobarbital per $100 \mathrm{~g}$ body weight by intraperitoneal injection.

All incubations of adipose tissue were carried out at $37^{\circ} \mathrm{C}$ in a Krebs-Ringer bicarbonate medium (KRB), gassed with 95 per cent $\mathrm{O}_{2}, 5$ per cent $\mathrm{CO}_{2}$ in stoppered 10 - or $125-\mathrm{ml}$ Erlenmeyer flasks. A Dubnoff metabolic shaker was used, oscillating 70 to 80 times per minute.

FFA were determined according to Dole and Meinertz (18) on $0.5-\mathrm{ml}$ aliquots of incubation medium and on 75to $100-\mathrm{mg}$ fragments of adipose tissue. The TBA method was modified slightly, as follows, from the technique described by Bernheim and Wilbur and their collaborators $(20,21)$. Two $\mathrm{ml}$ of test medium was placed in a large Pyrex test tube with $4 \mathrm{ml}$ of 20 per cent trichloroacetic acid (TCA) and a boiling bead. One $\mathrm{ml}$ of 0.75 per cent TBA was added, and the solution was stirred and placed in a boiling water bath for 20 minutes. After transfer to a centrifuge tube and centrifugation at 3,000 rpm for 20 minutes, the absorbance of the clear supernate was measured in Coleman tubes with a light path of $1 \mathrm{~cm}$ at $530 \mathrm{~m} \mu$ in a Coleman Junior spectrophotometer. Control medium was used for the reagent blank. The TBA reaction was also carried out on $125-$ to $225-\mathrm{mg}$ pieces of adipose tissue, macerated in $4 \mathrm{ml}$ of TCA. Then $2 \mathrm{ml}$ of $\mathrm{H}_{2} \mathrm{O}$ and $1 \mathrm{ml}$ of 0.75 per cent TBA were added. Manipulation thereafter was the same as for peroxide determination in the medium. 
The chromogen produced in the TBA reaction has been characterized as the condensation product of one molecule of malonylaldehyde with two of thiobarbituric acid (9). It is not possible to prepare a standard polyunsaturated fatty acid peroxide solution of known composition, and hence the TBA reaction generally has been quantitated only in absorbance units. Recently, Sinnhuber and $\mathrm{Yu}$ (8) have suggested the use of 1,1,3,3-tetraethoxy propane (TEP) as a standard for the TBA reaction. One mole of TEP hydrolyzes to 1 mole of malonylaldehyde and 4 moles of ethanol, thereby making possible the presentation of data in terms of malonylaldehyde production. This report did not come to our attention until the present study was virtually completed. However, using TEP as a standard for the TBA reaction carried out as described above, it may be calculated that an absorbance of 0.100 is equivalent to $1.1 \times 10^{-2} \mu$ moles of malonylaldehyde. The number of moles of malonylaldehyde which may be derived from any given unsaturated fatty acid in this system is not known, but is probably less than the number of double bonds.

Materials used were as follows: adrenaline hydrochloride, Parke, Davis and Company; glucagon (HGF)-free insulin from the Lilly Laboratory; quercitin from the $\mathrm{Nu}$ tritional Biochemicals Corporation; 2-thiobarbituric acid from Eastman Kodak Company; and crystalline bovine plasma albumin (BPA) from the Armour Laboratory.

\section{RESULTS}

Relation of lipid peroxidation to FFA release by adipose tissue in vitro. Having shown in studies reported elsewhere (17) that a TBA chromogen is formed during aerobic incubation of adipose tissue in vitro, the following study was designed to establish what, if any, relationship exists between the production of TBA chromogen and FFA release. Epididymal fat pads, weighing approximately $400 \mathrm{mg}$, were preincubated in $3.0 \mathrm{ml}$ of $\mathrm{KRB}$ (without albumin) to which had been added $10 \mu \mathrm{g}$ of adrenaline per $\mathrm{ml}$ to stimulate lipolysis or an equivalent volume of distilled water $(0.3 \mathrm{ml})$ as a control. At the end of 30 minutes the tissues were removed, washed in 0.9 per cent $\mathrm{NaCl}$ for 15 seconds, and then transferred to $10-\mathrm{ml}$ Erlenmeyer flasks containing $5 \mathrm{ml}$ of $\mathrm{KRB}$ with 4 per cent BPA and gassed with 95 per cent $\mathrm{O}_{2}, 5$ per cent $\mathrm{CO}_{2}$. The flasks were stoppered and incubated for 3 hours at $37^{\circ} \mathrm{C}$ in a Dubnoff shaker. TBA and FFA values at the end of incubation are plotted in Figure 2. A remarkably good correlation was found $(r=+0.85 ; p<0.01)$, suggesting that the unsaturated fatty acids which are peroxidized during the incubation are released in a relatively fixed relationship to the FFA. These

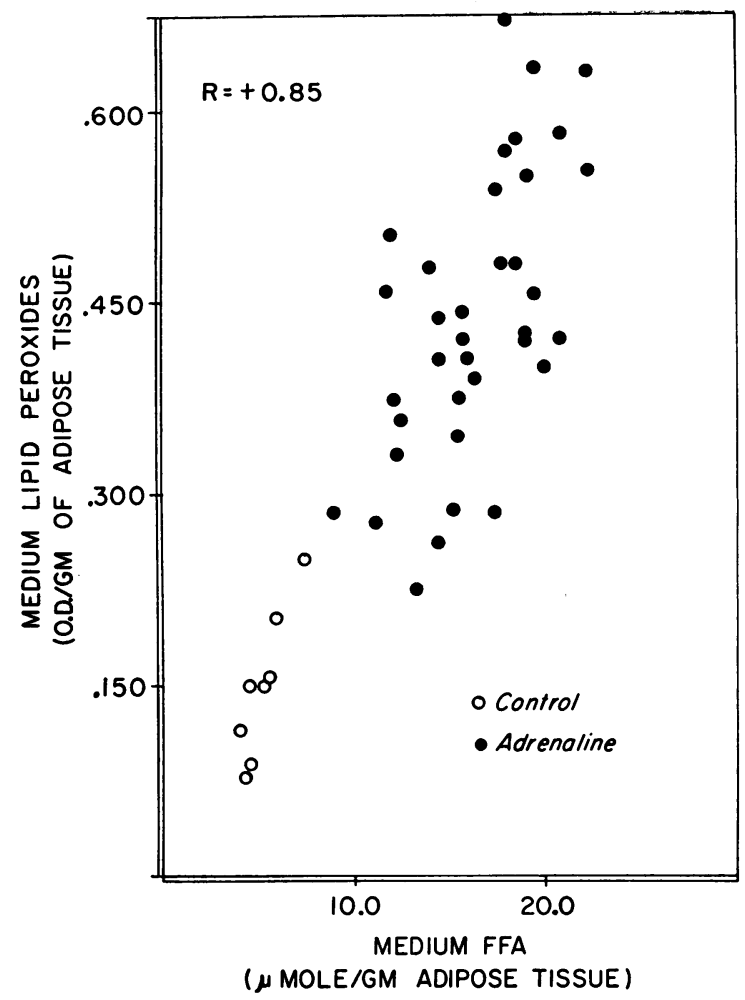

Fig. 2. Correlation between release of FFA and LIPID PEROXIDES ESTIMATED AS THE THIOBARBITURIC ACID Chromogen. See text for details.

results suggest that under the proper conditions TBA chromogen production might conceivably be used as an indicator of lipolysis.

Further data bearing on this possibility were obtained in experiments in which FFA release was

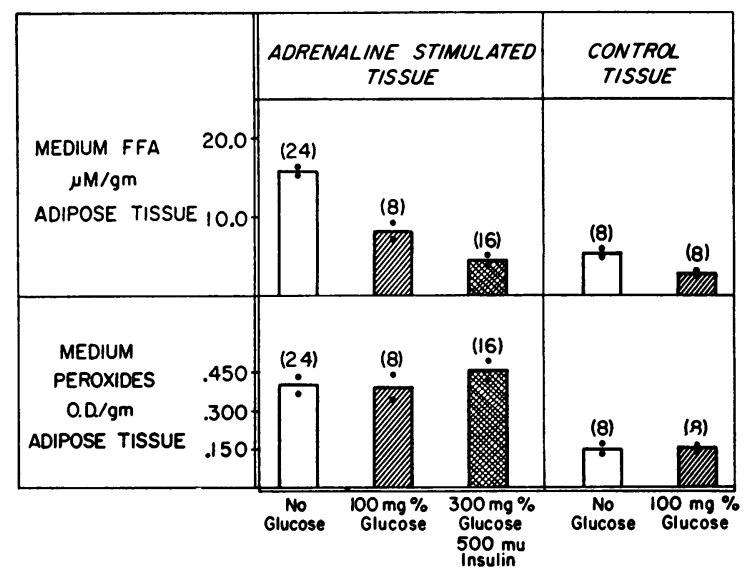

Fig. 3. INFLUENCE OF GLUCOSE AND INSULIN ON NET FFA AND TBA CHROMOGEN PRODUCTION BY CONTROL AND ADRENALINE-STIMULATED ADIPOSE TISSUE. 
depressed by incubating adipose tissue with glucose or with glucose and insulin. Under these conditions re-esterification of FFA is favored (22). Otherwise, the tissues were handled as in the previous experiment. Figure 3 shows that net FFA output is reduced by glucose and insulin, while the production of the TBA chromogen is unaltered compared to that in a medium free of glucose.

The dissociation between FFA and TBA chromogen production in the presence of glucose is illustrated even better in Figures 4 and 5, which plot cumulative FFA and TBA values during prolonged incubation in media with and without glucose. In these experiments entire epididymal fat pads were preincubated for 30 minutes in $20 \mathrm{ml}$ of $\mathrm{KRB}$ in 125-ml Erlenmeyer flasks, with or without adrenaline added to a concentration of $10 \mu \mathrm{g}$ per $\mathrm{ml}$. After rinsing, the fat pads were transferred to fresh KRB media with 4 per cent BPA, with and without $300 \mathrm{mg}$ glucose per $100 \mathrm{ml}$, and incubated for 10 hours. Aliquots were removed for estimation of FFA and TBA chromogen at the times indicated in the figures. As expected, tissues preincubated with adrenaline (Figure 5 ) re-

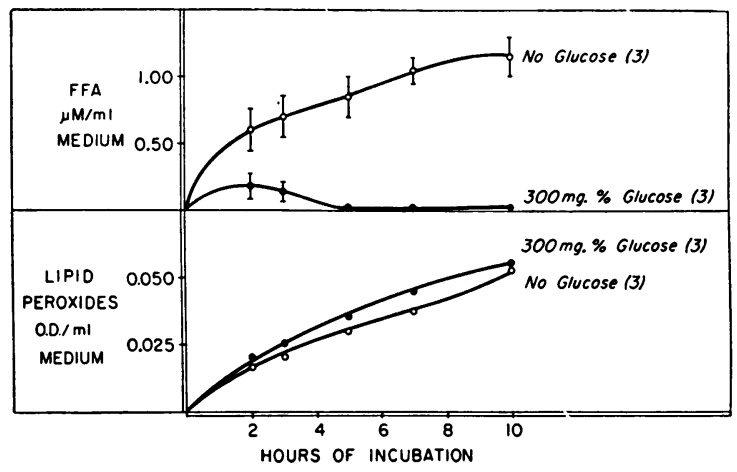

Fig. 4. INFLUENCE OF GLUCOSE ON NET FFA AND LiPID PEROXIDE PRODUCTION BY UNSTIMULATED ADIPOSE TISSUE DURING PROLONGED INCUBATION. See text for details.

leased more FFA and TBA chromogen than did those not so stimulated (Figure 4). In both circumstances, however, it is clear that, in the presence of glucose, FFA are eventually completely extracted from the medium, whereas the products of lipid peroxidation continue to accumulate. In the absence of glucose, concentrations of FFA and TBA chromogen increase in parallel, as in Figure 2. Lipid peroxidation is completely pre-

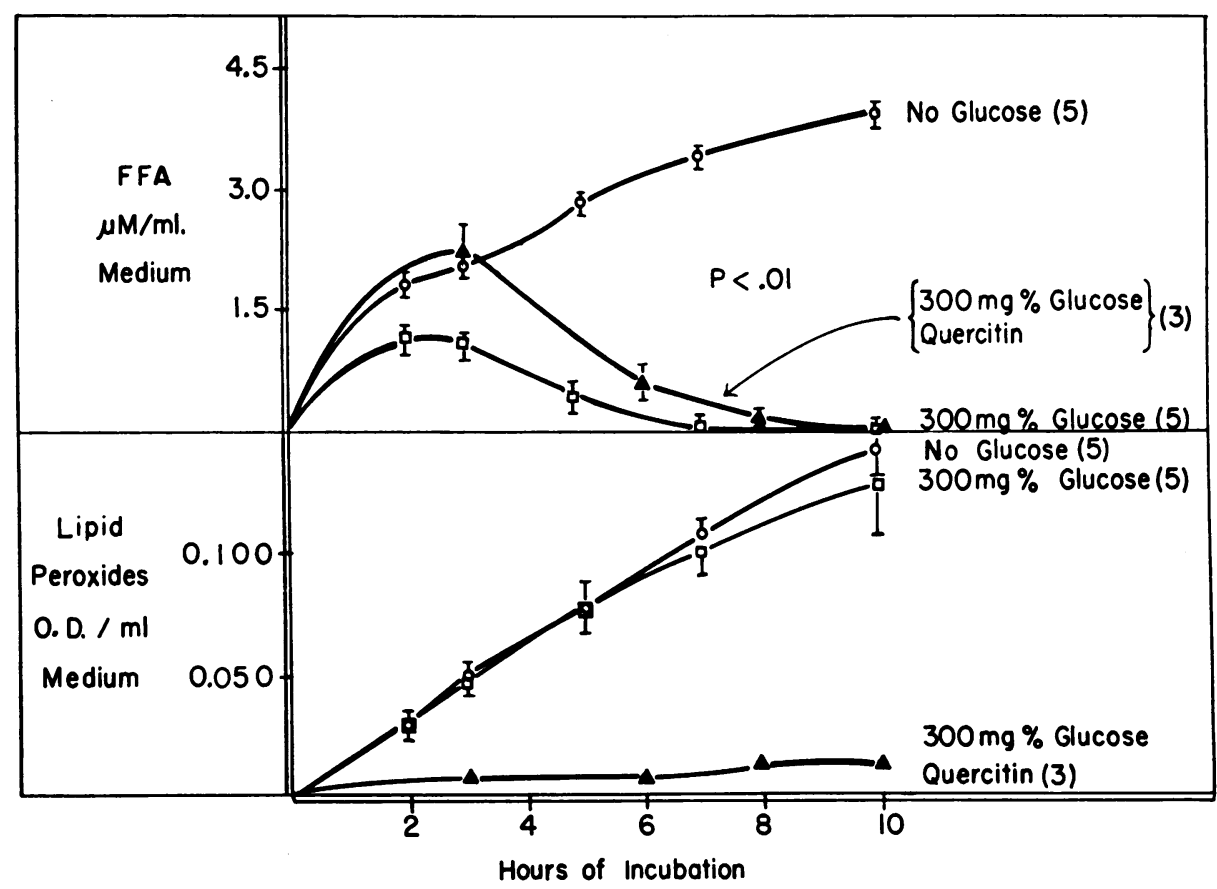

Fig. 5. In fluence of glucose and of Quercitin on Net FFA ANd Lipid PEROXide formaTION by adrenaline-Stimulated adipose tissue. Adipose tissue, 3.3 to $3.7 \mathrm{~g}$, was preincubated in $20 \mathrm{ml} \mathrm{KRB}$ containing $10 \mu \mathrm{g}$ adrenaline per $\mathrm{ml}$ (without albumin) for 30 minutes, then incubated for 10 hours in KRB +4 per cent BPA, with and without glucose. 
vented by $0.1 \mathrm{mM}$ quercitin, an antioxidant. No significance should be attached to the higher FFA levels in the quercitin experiment, since the latter was not carried out simultaneously with the other experiments but was simply plotted with them for convenience. In other experiments FFA levels were not influenced by quercitin (17).

This experiment may be criticized on the grounds that adipose tissue might no longer be viable during the latter part of the incubation. To check on the metabolic activity of the adipose tissue during prolonged incubation, the following experiment was done. Adipose tissue was preincubated with adrenaline for 30 minutes, as before, and then transferred to flasks containing 4 per cent BPA in KRB without glucose for 6 hours' incubation. At the end of this time aliquots were removed for FFA analysis. The initial volume was then restored with 4 per cent BPA-KRB. For half the flasks the added medium contained sufficient glucose to bring the final concentration to $300 \mathrm{mg}$ per $100 \mathrm{ml}$. At the end of 3 hours it was found that the adipose tissue in the flasks without glucose added $2.86 \pm 1.45 \mu$ moles of FFA per $\mathrm{g}$, whereas in the flasks with glucose $2.61 \pm 0.79$ $\mu$ moles of FFA per $g$ was abstracted from the medium (11 observations each). In short, there was a net gain by the tissue of $5.47 \mu$ moles of FFA as a result of adding glucose. We consider this to be good evidence for viability of the tissue between the sixth and ninth hour of incubation.

The disappearance of FFA during incubation in the glucose medium may be attributed to re-esterification of the fatty acids (22). The continued accumulation of TBA chromogen irrespective of the glucose content of the medium most likely represents the products of peroxidation of unsaturated fatty acids liberated from tissue triglycerides during lipolysis. Once peroxidized, they are no longer reutilizable by the tissue. These results give additional support to the suggestion that under appropriate conditions the estimation of the breakdown products of lipid peroxides may serve as a reflection of lipolysis as distinguished from the FFA estimation, which in the presence of glucose represents the net balance between production and utilization of fatty acids.

An alternate explanation for these results is that the unsaturated fatty acids which are the source of the TBA chromogen are less susceptible to re- esterification once liberated by hydrolysis than are saturated fatty acids. This possibilty was eliminated by the following experiment. Adipose tissue was incubated for 3 hours in a KRB medium with $300 \mathrm{mg}$ glucose per $100 \mathrm{ml}$ and 4 per cent bovine albumin to which had been added either palmitic acid or linolenic acid, according to the technique of Bragdon and Gordon (23). The palmitate-albumin flasks contained $7.92 \mu$ moles palmitic acid per flask, and the linolenic-albumin flasks contained $8.49 \mu$ moles linolenic acid per flask. At the end of the incubation the adipose tissue had extracted $3.64 \mu$ moles of FFA from the palmitate flasks and $3.66 \mu$ moles from the linolenic acid flasks, indicating that linolenic acid is readily utilized by adipose tissue in this system.

Lipid peroxide formation by adipose tissue from hypophysectomized rats. In a further study of lipid peroxidation, a series of observations was made with adipose tissue of normal and hypophysectomized rats. The tissue was preincubated with adrenaline and then incubated in KRB-albumin for 10 hours. There was no glucose in the medium. In agreement with other reports (1), adipose tissue from hypophysectomized rats released less FFA in response to adrenaline than did the normal tissue (Figure 6). Unexpectedly, however, production of TBA chromogen was found to be disproportionately depressed in the tissue from the hypophysectomized animals. Recalculation of the results on the basis of fat-free weights did not alter the outcome. As with the

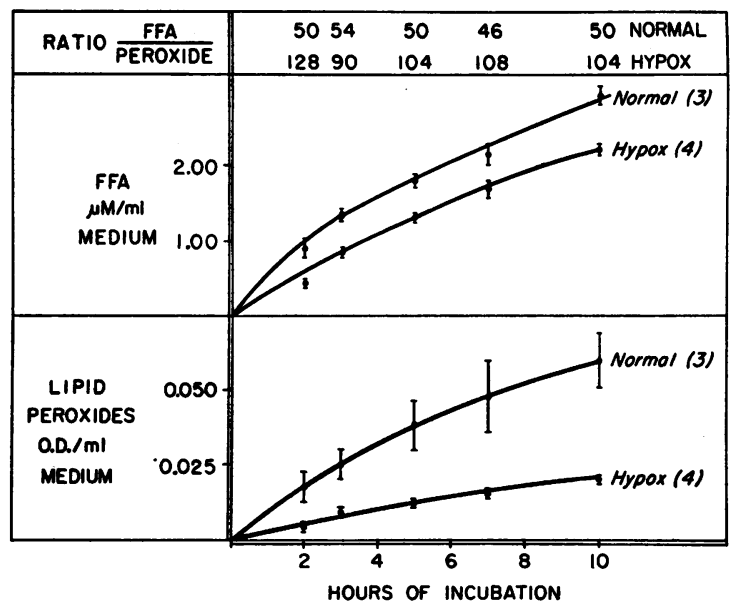

Fig. 6. FFA RELEASE AD LIPID PEROXIDE PRODUCTION BY ADRENALINE-STIMULATED ADIPOSE TISSUE OF NORMAL, AND HYPOPHYSECTOMIZED RATS. 
TABLE I

Influence of $\alpha$-tocopherol acetate on lipid peroxide formation by adipose tissue in vitro (4 rats) *

\begin{tabular}{|c|c|c|}
\hline Diet & $\underset{\text { peroxides }}{\text { Medium }}$ & $\underset{\text { FFA }}{\text { Medium }}$ \\
\hline & $A / g$ & umoles $/ \mathrm{g}$ \\
\hline $\begin{array}{l}\text { Chow } \dagger \\
\text { Chow +olive oil }+ \\
\text { Chow }+\alpha \text {-tocopherol acetate } \$\end{array}$ & $\begin{array}{l}0.522 \pm 0.026 \\
0.475 \pm 0.014 \\
0.182 \pm 0.012\end{array}$ & $\begin{array}{l}16.7 \pm 1.2 \\
20.7 \pm 1.1 \\
18.1 \pm 1.2\end{array}$ \\
\hline
\end{tabular}

* Adipose tissue was removed from rats fasted overnight, incubated in a KRB buffer without albumin and with $10 \mu \mathrm{g}$ of adrenaline $/ \mathrm{ml}$ for 30 minutes, and then transferred to fresh medium containing 4 per cent bovine plasma albumin for 3 hours. Values are means $\pm \mathrm{SE}$. Purina chow +liver pudding +lettuce, twice weekly.

Oliver oil, $0.5 \mathrm{ml}$ p.o., every other day.

$\S \alpha$-Tocopherol acetate, $5.0 \mathrm{mg}$ in $0.5 \mathrm{ml}$ olive oil p.o., every other day.

data in Figure 2, the ratio between FFA and lipid peroxides remained remarkably constant, but was twice as great in the hypophysectomized animals as in the controls, the average ratios being 106 and 50 , respectively.

Influence of $d, \alpha$-tocopherol acetate on lipid peroxide formation. The unexpected finding that adipose tissue from hypophysectomized rats had a proportionately greater reduction in lipid peroxide formation and release than in FFA release led to investigations of the nutritional status of the rats with respect to vitamin $\mathrm{E}$. It is known that tocopherol requirements are increased during periods of active growth. Furthermore, several investigators have emphasized that rat chow diets are marginal in their tocopherol content $(24,25)$. Since the formation of lipid peroxides is characteristic of vitamin E deficiency (14), the possibility was considered that the adipose tissue of the normal rats produced peroxides because of relative tocopherol deficiency, against which the hypophysectomized rats were protected by their lesser need for the vitamin because of their low metabolic rate and impaired growth. As a first step in exploring this possibility, the chow diet of a group of normal rats was supplemented with $5 \mathrm{mg}$ of $d, \alpha$-tocopherol acetate in olive oil every other day for 10 days. On the eleventh day the rats were sacrificed and the adipose tissue removed for incubation with adrenaline, as in previous experiments. Table I shows that this treatment markedly reduced peroxide formation in comparison to the unsupplemented controls. From these results it may be suggested that a deficiency of vitamin $\mathrm{E}$ in the chow diet contributes significantly to the development of lipid peroxidation in adipose tissue incubated in vitro.

\section{DISCUSSION}

This report considers some of the metabolic, hormonal, and nutritional factors influencing lipid peroxidation, as reflected in the TBA reaction, in rat adipose tissue in vitro. Elsewhere, data will be found bearing on the mechanism of lipid peroxidation in this tissue, with particular reference to the role of cofactors which contaminate human and bovine serum albumin and promote peroxidation (17). Both studies demonstrate the production of a TBA-reacting chromogen by adipose tissue. The data of Ball, Blackard and Engel (17), considered in relation to studies by others $(10-14,16$, $20)$, leave little doubt that this chromogen represents malonylaldehyde, presumably derived by acid hydrolysis of polyunsaturated fatty acid peroxides and hydroperoxides.

The original source of the TBA chromogen during incubation of adipose tissue was not established. It would seem a reasonable assumption that it was derived chiefly from the peroxidation of polyunsaturated fatty acids released during the hydrolysis of triglycerides, in view of its close correlation with FFA production, particularly when lipolysis was stimulated by adrenaline and there was no glucose in the medium. Elsewhere, evidence is presented that peroxidation takes place within the tissue and not in the medium (17). When albumin-linolenate is incubated with adipose tissue in the absence of glucose, and under conditions in which little or no linolenic acid is taken up by the tissue, no significant amount of TBA chromogen is formed. However, if the tissue is permitted to assimilate the linolenate by incorporating glucose in the medium and lipolysis is then stimulated by adrenaline, significant amounts of TBA chromogen appear in the medium. If palmitate is used in place of linolenate, chromogen production is significantly less (26). Finally, it has also been shown in a variety of experiments that the incubation medium may be incubated as long as 10 hours after removal of the adipose tissue without any increase in TBA values. Peroxidation of unsaturated fatty acids of phospholipids and cholesterol esters might also conceivably occur during incubation, but it seems unlikely that these would contribute significantly, in view of the relatively small amounts of these lipids in adipose tissue. 
The striking correlation between FFA and TBA chromogen release, when adipose tissue is incubated under conditions in which reutilization of FFA is minimized, suggests that the TBA reaction may reflect lipolysis. In the glucose-containing medium from which FFA are efficiently removed after initial accumulation in response to adrenaline stimulation, the TBA chromogen continues to increase in a linear fashion during the incubation. This strongly implies that once the unsaturated fatty acids have been peroxidized, they are no longer available for re-esterification. Whether their fate in adipose tissue is other than decomposition to the various products which have been described as resulting from rancidification in general (5) cannot be stated. Nevertheless, the study does present a possible application of the TBA reaction to permit the distinction between free fatty acid release and flux in adipose tissue incubated in vitro.

If the TBA values may be interpreted in this fashion, the data give added support to the evidence already available that the rate of lipolysis per se is not modified by glucose and insulin (1). Only the rate of re-esterification of FFA is altered, and this in turn accounts for the lesser net accumulation of FFA in the presence of glucose in the medium. With regard to the effects of adrenaline in vitro on FFA and TBA chromogen, it is interesting that in 1950 Donnan reported that, after treatment of rats with adrenaline, liver and brain homogenates showed increased TBA values after 3 hours' incubation in vitro (27).

The observation that adipose tissue of hypophysectomized rats forms less lipid peroxides in relation to FFA after adrenaline stimulation was an interesting but unanticipated finding. Sufficient data are not yet available to account for this finding, but it is reasonable to speculate that the vitamin $\mathrm{E}$ requirement of the hypophysectomized animal may be less than that of normal rats. There is evidence that the need for vitamin $\mathrm{E}$ is increased during periods of active growth and metabolism. The manifestations of vitamin $\mathrm{E}$ deficiency may be brought out locally by stimulating growth, as in the uterus of the estrogen-treated animal (28), or in a more general way by increasing the metabolic rate of animals by feeding thyroid substance $(29,30)$. Studies are in progress to establish whether the hypophysectomized rat does in fact have a lesser requirement for vitamin $\mathrm{E}$, and to determine what hormonal deficiencies are responsible for this protection. It should be noted, however, that there are alternative explanations for our findings. For example, if the adipose tissue of hypophysectomized rats were to contain a lesser proportion of unsaturated fatty acids, the likelihood of peroxidation would be reduced, as would be the requirement for vitamin $\mathrm{E}$. The studies with vitamin $\mathrm{E}$ supplementation in the normal rats serve only to show that tocopherol deficiency contributes in an important way to the production of lipid peroxides in the adipose tissue of the "normal" rats, but further studies are necessary to establish that the chow diet adequately meets the vitamin $\mathrm{E}$ requirement of hypophysectomized rats.

Our findings have a number of important implications for the interpretation of metabolic studies with adipose tissue. First, if one may use lipid peroxide production as a pathognomonic feature of vitamin $\mathrm{E}$ deficiency, then it must be concluded that adipose tissue is particularly susceptible to this deficiency, and that tocopherol deficiency is a factor which complicates to an undetermined degree the interpretation of all experiments with rats maintained on commercial rations. Involvement of adipose tissue is, of course, a well known feature of vitamin $\mathrm{E}$ deficiency $(31,32)$. Second, in evaluating studies with adipose tissue in vitro, it must now be determined whether lipid peroxides formed during incubation influence any metabolic activities qualitatively or quantitatively. Lipid peroxides are known to be damaging to various enzyme systems $(10,33,34)$, and peroxidation of unsaturated fatty acids in cell membranes or subcellular particles would be expected to lead to serious functional derangements. Finally, even if peroxidation in adipose tissue is reduced to a minimum by using dialyzed, EDTA-treated albumin, we must now establish whether tocopherol deficiency, which seems to be ubiquitous in chowfed rats, influences adipose tissue metabolism independently of the effects mediated by lipid peroxidation. Such studies are in progress.

\section{SUM M ARY}

1. Rat adipose tissue incubated aerobically in vitro in a Krebs-Ringer bicarbonate medium with bovine plasma albumin releases a substance which 
yields a chromogen when reacted with 2-thiobarbituric acid (TBA). The chromogen is presumed to represent the interaction of TBA with malonylaldehyde, a product of the peroxidation of polyunsaturated fatty acids.

2. Adrenaline increases the production of the TBA chromogen. Provided there is no glucose in the medium, there is a high correlation between free fatty acid (FFA) and TBA chromogen release into the medium.

3. When adipose tissue which has been stimulated to a high rate of lipolysis by adrenaline is incubated in a medium with a high concentration of glucose, FFA are eventually completely extracted from the medium, while the TBA chromogen progressively accumulates. These data suggest that the measurement of the products of peroxidation of unsaturated fatty acids may reflect lipolysis under conditions in which FFA values represent the net result of release and reutilization of fatty acids.

4. FFA release by adipose tissue in vitro in response to adrenaline is reduced after hypophysectomy, but lipid peroxidation is disproportionately lowered. Incorporation of $\alpha$-tocopherol into the chow diet of the normal rat lowers TBA chromogen production to that of the hypophysectomized rat, without altering FFA release. These data suggest a role for the pituitary in determining tocopherol requirements, and illustrate an application of the TBA reaction in adipose tissue to the study of vitamin $\mathrm{E}$ economy.

\section{ACKNOWLEDGMENT}

We are indebted to Dr. Frederick Bernheim for helpful discussions during the course of this work.

\section{REFERENCES}

1. Engel, F. L., and White, J. E., Jr. Some hormonal influences on fat mobilization from adipose tissue. Amer. J. clin. Nutr. 1960, 8, 691.

2. Lymn, W. S., MacLeod, R. M., and Brown, R. H. Effects of epinephrine, insulin, and corticotrophin on the metabolism of rat adipose tissue. J. biol. Chem. 1960, 235, 1904.

3. Cahill, G. F., Jr., Leboeuf, B., and Renold, A. E. Factors concerned with the regulation of fatty acid metabolism by adipose tissue. Amer. J. clin. Nutr. 1960, 8, 733.

4. Freinkel, N. Extrathyroidal actions of pituitary thyrotropin: Effects on the carbohydrate, lipid and respiratory metabolism of rat adipose tissue. J. clin. Invest. 1961, 40, 476.

5. Yu, T. C., Day, E. A., and Sinnhuber, R. O. Autoxidation of fish oils. I. Identification of volatile monocarbonyl compounds from autoxidized salmon oil. J. Food Sci. 1961, 26, 192.

6. Maier, V. P., and Tappel, A. L. Products of unsaturated fatty acid oxidation catalyzed by hematin compounds. J. Amer. Oil Chem. Soc. 1959, $36,12$.

7. Yu, T. C., and Sinnhuber, R. O. 2-Thiobarbituric acid method for the measurement of rancidity in fishery products. Food Technol. 1957, 11, 104.

8. Sinnhuber, R. O., and $\mathrm{Yu}$, T. C. 2-Thiobarbituric acid method for the measurement of rancidity in fishery products. II. The quantitative determination of malonaldehyde. Food Technol. 1958, 12, 9.

9. Sinnhuber, R. O., Yu, T. C., and Yu, T. C. Characterization of the red pigment formed in the 2-thiobarbituric acid determination of oxidative rancidity. Food Res. 1958, 23, 626.

10. Barber, A. A., and Ottolenghi, A. Effect of ethylenediaminetetraacetate on lipide peroxide formation and succinoxidase inactivation by ultraviolet light. Proc. Soc. exp. Biol. (N. Y.) 1957, 96, 471.

11. Bernheim, F., Ottolenghi, A., and Wilbur, K. M. Studies on bone marrow lipid in normal and irradiated rabbits. Radiat. Res. 1956, 4, 132.

12. Bieri, J. G., and Anderson, A. A. Peroxidation of lipids in tissue homogenates as related to vitamin E. Arch. Biochem. 1960, 90, 105.

13. Zalkin, H., and Tappel, A. L. Studies of the mechanism of vitamin $\mathrm{E}$ action. IV. Lipide peroxidation in the vitamin E-deficient rabbit. Arch. Biochem. 1960, 88, 113.

14. Ottolenghi, A. Interaction of ascorbic acid and mitochondrial lipides. Arch. Biochem. 1959, 79, 355.

15. Philpot, J. St.L., and Roodyn, D. B. A comparison between the effects in mice of injected organic peroxides and of whole body $\mathrm{x}$-irradiation. Int. $\mathrm{J}$. radiat. Biol. 1959, 1, 372.

16. Horwitt, M. K. Vitamin $\mathrm{E}$ and lipid metabolism in man. Amer. J. clin. Nutr. 1960, 8, 451.

17. Ball, M. F., Blackard, W. G., and Engel, F. L. Lipide peroxidation by rat adipose tissue in vitro. To be published.

18. Dole, V. P., and Meinertz, H. Microdetermination of long-chain fatty acids in plasma and tissues. J. biol. Chem. 1960, 235, 2595.

19. Engel, F. L., Schiller, S., and Pentz, E. I. Studies on the nature of the protein catabolic response to adrenal cortical extract. Endocrinology 1949, 44, 458.

20. Bernheim, F., Bernheim, M. L. C., and Wilbur, K. M. The reaction between thiobarbituric acid and the oxidation products of certain lipides. J. biol. Chem. 1948, 174, 257. 
21. Wilbur, K. M., Bernheim, F., and Shapiro, O. W. The thiobarbituric acid reagent as a test for the oxidation of unsaturated fatty acids by various agents. Arch. Biochem. 1949, 24, 305.

22. Raben, M. S., and Hollenberg, C. H. Effect of glucose and insulin on the esterification of fatty acids by isolated adipose tissue. J. clin. Invest. 1960, 39, 435.

23. Bragdon, J. H., and Gordon, R. S., Jr. Tissue distribution of $\mathrm{C}^{14}$ after the intravenous injection of labeled chylomicrons and unesterified fatty acids in the rat. J. clin. Invest. 1958, 37, 574.

24. György, P., and Rose, C. S. Tocopherol and hemolysis in vivo and in vitro. Ann. N. Y. Acad. Sci. 1949, 52, 231.

25. Kitabachi, A. E., McCay, P. B., Carpenter, M. P., Trucco, R. E., and Caputto, R. Formation of malonaldehyde in vitamin $\mathrm{E}$ deficiency and its relation to the inhibition of gulonolactone oxidase. J. biol. Chem. 1960, 235, 1591.

26. Ball, M. F., and Engel, F. L. Peroxidation of linolenic acid by rat adipose tissue in vitro. Fed. Proc. 1962, 21, 286.

27. Donnan, S. K. The thiobarbituric acid test applied to tissues from rats treated in various ways. J. biol. Chem. 1950, 182, 415.
28. Atkinson, W. B., Kaunitz, H., and Slanetz, C. A. Effects of ovarian hormones upon uterine pigmentation in vitamin E-deficient rats. Ann. N. Y. Acad. Sci. 1949, 52, 68.

29. Wheeler, R. S., and Perkinson, J. D., Jr. The influence of induced hypo- and hyperthyroidism on vitamin $\mathrm{E}$ requirement of chicks. Amer. J. Physiol. 1949, 159, 287.

30. Tentori, L., Toschi, G., and Vivaldi, G. The effect of experimental hyperthyroidism on the appearance of muscle lesions in rats fed a vitamin E-deficient diet. R. C. Ist. sup. Sanità 1954, 17, 106.

31. Dam, H., and Granados, H. Peroxidation of body fat in vitamin $\mathrm{E}$ deficiency. Acta physiol. scand. 1945, 10, 162.

32. Filer, L. J., Rumery, R. E., and Mason, K. E.. Pigmentation of adipose tissue as influenced by unsaturated fatty acids in vitamin $\mathrm{E}$ deficient rats (abstract). Anat. Rec. 1947, 97, 387.

33. Wills, E. D. The effect of some organic peroxides on sulphydryl enzymes. Biochem. Pharmacol. 1959, 2, 276.

34. Tappel, A. L., Brown, W. D., Zalkin, H., and Maier, V. P. Unsaturated lipid peroxidation catalyzed by hematin compounds and its inhibition by vitamin $\mathrm{E}$. J. Amer. Oil Chem. Soc. 1961, 38, 5. 